\title{
Auto-titrating versus fixed-EPAP intelligent volume-assured pressure support (iVAPS) ventilation in patients with COPD and hypercapnic respiratory failure
}

\begin{abstract}
Background: Intelligent volume-assured pressure support (iVAPS) is a new noninvasive ventilation (NIV) mode that can automatically adjust pressure support to deliver effective ventilation. Our aim was to compare treatment efficacy and level of satisfaction between auto-titrating expiratory positive airway pressure (auto-EPAP) and fixed expiratory positive airway pressure (fixed-EPAP) during iVAPS treatment in stable hypercapnic chronic obstructive pulmonary disease (COPD) patients.

Material and methods: In this prospective single-blinded, randomized study, 50 patients with chronic stable hypercapnia (COPD) who met the study criteria were randomized into a group I treated with auto-EPAP and a group II who received fixed-EPAP during iVAPS treatment for 5 consecutive days. The patients' characteristics, arterial blood gases, and lung function test were recorded. Numeric rating scale (NRS), dyspnea and comfort scale were obtained. The study subjects were evaluated and followed up after initiating therapy for 5 consecutive days. Outcome measures were recorded at baseline (T0) and after three (T1) and five (T2) days of each consecutive period All parameters were collected and statistically analyzed.

Result: No significant differences were found regarding age, sex, or BMI between the both groups. It was noted that daytime $\mathrm{PaCO}_{2}$ decreased significantly over the follow-up period in the group I patients treated with auto-EPAP as compared with fixed-EPAP. Regarding the patient comfort and dyspnea during iVAPS treatment, dyspnea sensation was significantly lower with auto-EPAP $7.9 \pm 1.8$ (T0) vs $3.5 \pm 1.1$ (T2), $\mathrm{p}=0.001$ and fixed-EPAP $7.7 \pm 1.9$ (T0) vs $3.4 \pm 1.6$ (T2), $\mathrm{p}=0.001$, but no significance was reached between the both groups. However, auto-EPAP demonstrated significant improvement in comfort when compared with fixed-EPAP modality. However, the overall satisfaction of the patients receiving auto-EPAP modality was significantly increased. Mean tidal volume tended to be higher in auto-EPAP $698 \pm 213 \mathrm{~mL}$ compared with $628 \pm 178 \mathrm{~mL}$ in fixed-EPAP $(p=0.001)$. The air leak was significantly lower in auto-adjusting mode $(2.5 \pm 1.3 \mathrm{vs} 3.7 \pm 2.2 \mathrm{~L} / \mathrm{min})$ in fixed-EPAP modality. Conclusion: Auto-titrating NIV mode may provide additional benefit in decreasing $\mathrm{PaCO}_{2}$ more efficiently and improve patient comfort and satisfaction.
\end{abstract}

Key words: noninvasive ventilation, hypercapnic respiratory failure

Adv Respir Med. 2021; 89: 277-283

\section{Introduction}

Chronic obstructive pulmonary disease (COPD) is a progressive and debilitating respiratory condition; it is the only leading cause of death that is still increasing. COPD patients who develop hypercapnic respiratory failure have a particularly poor prognosis [1].

The pathophysiological processes underlying chronic hypercapnic respiratory insufficiency in COPD are not completely understood, the possible mechanisms may be contributed to derange- ments in ventilatory mechanics, muscle function, and gas exchange [2].

The role of nocturnal noninvasive ventilation (NIV) has been shown to improve outcome in acute hypercapnic respiratory failure due to COPD exacerbations. Still, however, the clinical efficacy of long-term home NIV (LTH-NIV) for management of COPD patients with chronic respiratory failure is limited [3].

Currently, among NIV modalities, volume-targeted (VT) modes are new hybrid possibilities incorporating features of both volume and pressure

Address for correspondence: Doaa Mohamed Magdy, Department of Chest, Faculty of Medicine, Assiut University Hospital, Assiut University, Assuit, 71515, Egypt; e-mail: doaamagdy_2020@aun.edu.eg/doaamagdy_2020@yahoo.com

DOI: 10.5603/ARM.a2021.0056 | Received: 14.01.2021 | Copyright (C 2021 PTChP | ISSN 2451-4934 | e-ISSN 2543-6031

This article is available in open access under Creative Common Attribution-Non-Commercial-No Derivatives 4.0 International (CC BY-NC-ND 4.0) license, allowing to download articles and share them with others as long as they credit the authors and the publisher, but without permission to change them in any way or use them commercially. 
ventilation. Intelligent volume-assured pressure support (iVAPS) ventilation uses an automated algorithm to adjust inspiratory pressure support (PS) within a predetermined range to maintain appropriate target ventilation. It offers an advantage to standard pressure support (NIV) modes and may improve patient comfort and compliance. Besides, they might have clinical benefits such as maintained airway patency and improved sleep quality [4].

Previous studies have examined iVAPS mode in treatment of chronic respiratory insufficiency or failure, e.g. obesity hypoventilation and neuromuscular disease. The pathophysiologic mechanisms of COPD are complex and multifactorial. There may be limited ability to provide NIV titration for these complex patients. In addition, the ventilatory requirements and upper airway support needs may change over time due to disease progression and alteration of lung mechanics that usually occurs in COPD patients. Therefore, an automatically adjusting expiratory positive airway pressure (auto-EPAP) algorithm may offer benefits over manually adjusted EPAP. Such an auto-EPAP algorithm has been recently incorporated into iVAPS mode reducing expiratory airway collapse in COPD patients and resulting in more homogenous ventilation [5].

The purpose of this study was to compare auto-titrating (auto-EPAP) versus fixed-EPAP during intelligent volume-assured pressure support (iVAPS) treatment in patients with COPD and chronic hypercapnia in terms of treatment efficacy, and patient satisfaction.

\section{Matherials and methods}

This prospective single-blinded, randomized study was conducted over one year from November 2018 to November 2020 at Assiut University Hospital. The study was conducted in accordance with the Declaration of Helsinki. It was approved by the Faculty of Medicine Ethics Committee, Assiut University. All the patients provided written informed consent before being enrolled in the study.

Inclusion criteria: COPD patients aged 45-75 with stable chronic hypercapnia at rest (partial pressure of carbon dioxide $\left[\mathrm{PaCO}_{2}\right]<50 \mathrm{~mm} \mathrm{Hg}$ ) [6] and ability to provide written informed consent. All patients using NIV in spontaneous-timed (ST) or VAPS mode for $\geq 3$-month duration with EPAP settings reviewed within the previous 12 months were included.
Exclusion criteria: Patients with unstable hemodynamic and respiratory conditions, e.g., recent acute heart failure, respiratory exacerbation or infection with worsening symptoms within the last month, malignancies, non-compliance with NIV (average usage of $<4 \mathrm{~h} /$ night), pre-existing conditions: severe bullous lung disease, pneumothorax or pneumomediastinum, pulmonary embolism, Sleep-disordered breathing (overlap syndrome, obesity hypoventilation).

Patients characteristics including age, sex, body mass index (BMI) smoking habit, e.g. current smoker, never smoker, ex-smoker; year of COPD diagnosis were recorded.

Spirometry (VMax 6150, SensorMedics, Yorba Linda, CA) at the time of the study were performed. Lung function parameters $\left(\mathrm{FEV}_{1}, \mathrm{FVC}\right.$, $\mathrm{FEV}_{1} / \mathrm{FVC}$ ) were obtained from all patients. Also, predicted lung volumes and voluntary respiratory muscle strength values) MIP and MEP) were recorded as recommended $[7,8]$.

Arterial blood gas (ABG) (Model 850, Chiron Diagnostics, Medfield, MA) pH, $\mathrm{PaCO}_{2}, \mathrm{PaO}_{2}$, $\mathrm{SaO}_{2}$, and $\mathrm{PaO}_{2} / \mathrm{FiO}_{2}$ were performed on room air for all patients. The sample was taken during the initial assessment appointment after the study consent to ensure that the patients were clinically stable before the study.

Randomization and treatment settings: During an in-hospital stay of several days, eligible patients were commenced for treatment with auto-EPAP (Group I) and fixed-EPAP (Group II) during iVAPS [Astral 150, ResMed Corp. iVAPS device algorithms] treatment for 5 consecutive days. Randomization was performed $1: 1$ by a laboratory scientist not involved with the study using the technique of shuffled sealed envelopes containing equal numbers of each treatment arm (Figure 1).

iVAPS settings were automatically determined following a $60 \mathrm{~min}$ intelligent 'learn' period during awake spontaneous breathing on $4 \mathrm{~cm} \mathrm{H}_{2} \mathrm{O}$ expiratory positive airway pressure (EPAP). The ventilator automatically adjusted the treatment target Va, and the backup RR based on spontaneous RR, flow rates and estimated anatomical dead space. EPAP was titrated in response to either a flow limitation, taking into account overnight saturation and $\mathrm{PtcCO}_{2}$, ventilator data, and/or the patient symptoms and tolerance. Thus, iVAPS with auto-EPAP settings were instructed to keep the range "open", so the algorithm could be tested across the full range: EPAP is adjusted within EPAP minimum: $5 \mathrm{~cm} \mathrm{H}_{2} \mathrm{O}$, EPAP max: $15 \mathrm{~cm} \mathrm{H}_{2} \mathrm{O}$, PS maximum: $20 \mathrm{~cm} \mathrm{H}_{2} \mathrm{O}$, PS min- 


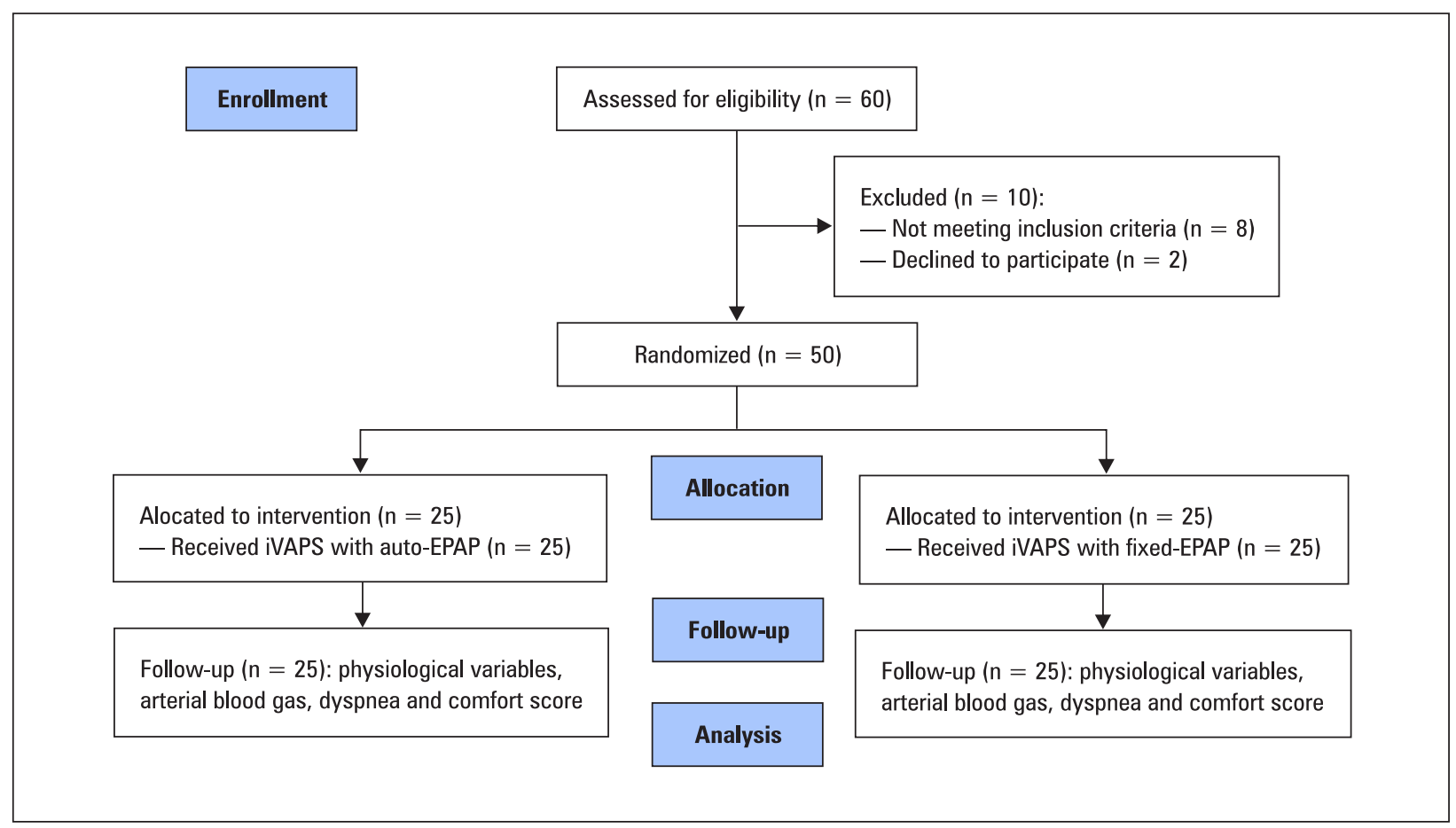

Figure 1. Flow diagram chart

imum: $5 \mathrm{~cm} \mathrm{H}_{2} \mathrm{O}$. The target tidal volume was set as $6 \mathrm{~mL} / \mathrm{kg}$ of the patient's ideal body weight to maintain optimal alveolar ventilation (Va) at a respiratory rate (RR) matched to their own.

NIV iVAPS was delivered via either a nasal or oronasal mask, and the mask was carefully adjusted as part of routine clinical care.

Additional oxygen at a fixed inspiratory fraction $\left(\mathrm{FiO}_{2}\right)$ was added when required with the scope to maintain the oxygen saturation $\left(\mathrm{SaO}_{2}\right)$ level above $90 \%$.

\section{Measurements}

- Physiological variables including exhaled VT, respiratory rate (RR), heart rate, and arterial blood gas (ABG) were recorded at baseline (T0) and then after 3 (T1) and 5 (T2) days of each consecutive period of the treatment courses. Time zero was defined as the initiation of iVAPS ventilation.

- Subjective assessment of dyspnea was determined using a numerical rating scale [9]. NRS consists of a scale numbered (0-10), $0=$ 'Not breathless at all' and $10=$ 'Breathlessness as bad as you can imagine'. A higher score represents greater symptom severity.

- The patient comfort [10] was assessed at each time period of treatment at baseline and after 3 and 5 days. All patients were asked to grade the comfort of the device (1-10) using the following scale: 1 = severe discomfort; and $10=$ very good level of comfort.

- The overall patient satisfaction level was assessed in the morning. All subjects have completed a visual analog satisfaction (VAS) questionnaire. The patients scored satisfaction (0-10) of their experience from the previous night. Questions included: 1) How well did you sleep last night? 2) How rested do you feel this morning? 3) How often did you wake during the night? 4) How uncomfortable was your iVAPS pressure? 5) Overall, how satisfied were you with your quality of sleep last night?

- The patient's compliance to iVAPS was recorded using the ResScan software within the machine and included (number of hours/ /night of use and leak).We used a sample size of 25 for each group for this study based on our ethics committee recommendation.

\section{Statistical analysis}

Statistical package for the social sciences (SPSS), version 20 (produced by IBM SPSS Statistics for Windows, version 20; IBM Corp., Armonk, New York, USA) software was used for the collected data. Normally distributed data were expressed as means \pm standard deviation, using $\mathrm{t}$ tests or the Mann-Whitney U-test for comparison between the two study groups. Whereas 
Table 1. Patients' characteristics, baseline lung function test and blood gases of the study group $(\mathrm{n}=\mathbf{5 0})$

\begin{tabular}{|c|c|c|c|}
\hline & $\begin{array}{c}\text { Group I } \\
\text { Auto-EPAP modality } \\
(\mathrm{n}=25)\end{array}$ & $\begin{array}{c}\text { Group II } \\
\text { Fixed-EPAP modality } \\
(\mathbf{n}=25)\end{array}$ & P-value \\
\hline Age [years] & $58.2 \pm 3.3$ & $56.3 \pm 5.6$ & 0.231 \\
\hline Sex (male [\%]) & $12(48 \%)$ & $15(60 \%)$ & 0.034 \\
\hline BMI $\left[\mathrm{kg} / \mathrm{m}^{2}\right]$ & $27.4 \pm 4.1$ & $27.9 \pm 3.4$ & 0.543 \\
\hline Years of COPD diagnosis & $8.3 \pm 4.2$ & $8.2 \pm 5.7$ & 0.342 \\
\hline \multicolumn{4}{|l|}{ Arterial blood gases } \\
\hline $\mathrm{PH}$ & $7.37 \pm 0.03$ & $7.37 \pm 0.02$ & 0.345 \\
\hline $\mathrm{PaCO}_{2}[\mathrm{~mm} \mathrm{Hg}]$ & $62.7 \pm 6.6$ & $63.3 \pm 6.5$ & 0.321 \\
\hline $\mathrm{PaO}_{2}[\mathrm{~mm} \mathrm{Hg}]$ & $73.1 \pm 9.2$ & $72.8 \pm 10.4$ & 0.361 \\
\hline $\mathrm{SaO}_{2}[\%]$ & $95 \pm 2$ & $95 \pm 2$ & 0.323 \\
\hline $\mathrm{PaO}_{2} / \mathrm{FiO}_{2}$ & $262.2 \pm 38.3$ & $264.5 \pm 34.1$ & 0.251 \\
\hline \multicolumn{4}{|l|}{ Pulmonary function } \\
\hline FVC actual & $1.62 \pm 0.68$ & $1.43 \pm 0.84$ & 0.073 \\
\hline FVC [\%pred] & $64.2 \pm 15.1$ & $65.6 \pm 16.3$ & 0.177 \\
\hline $\mathrm{FEV}_{1}$ actual & $0.89 \pm 0.21$ & $0.87 \pm 0.24$ & 0.076 \\
\hline $\mathrm{FEV}_{1}[\%$ pred] & $47.2 \pm 9.5$ & $46.8 \pm 7.4$ & 0.235 \\
\hline $\mathrm{FEV}_{1} / \mathrm{FVC}$ & $49.1 \pm 13.4$ & $48.6 \pm 11.2$ & 0.663 \\
\hline RV [L] & $3.78 \pm 0.29$ & $3.58 \pm 0.34$ & 0.342 \\
\hline TLC [L] & $5.45 \pm 0.15$ & $5.54 \pm 0.63$ & 0.321 \\
\hline MIP [\%pred] & $42.4 \pm 16.3$ & $39.9 \pm 20.8$ & 0.54 \\
\hline MEP [\%pred] & $68.0 \pm 38.4$ & $69.1 \pm 46.7$ & 0.43 \\
\hline
\end{tabular}

Values are mean (SD). $\mathrm{BMI}$ — body mass index; $\mathrm{PaCO}_{2}$ — partial arterial carbon dioxide pressure; $\mathrm{PaO}_{2}$ — partial arterial oxygen pressure; $\mathrm{FEV}$ — forced expiratory volume in $1 \mathrm{~s}$; FVC — forced vital capacity; RV — residue volume; TLC — total lung capacity; MIP and MEP — maximal inspiratory and expiratory pressure

numeric data were expressed as a percentage (\%) using $\chi 2$ or Fisher's exact probability tests.

The comparison of vital signs and arterial blood gas analyses at multiple time intervals was performed by repeated measures analysis of variance, or non-parametric test of multiple correlated samples (Friedman test for heterogeneity of variance or the skewed distributed data), in which the significance level was adjusted using the Bonferroni correction method. A p-value of less than 0.05 was considered significant.

\section{Results}

A total of 50 stable hypercapnic COPD patients were included in the study. After randomization, 25 individuals were assigned to auto-EPAP - group I and 25 patients with fixed-EPAP - group II during iVAPS treatment.

The patients' characteristics and baseline lung function and arterial blood gases are presented in Table 1.
In both groups, it was noted that daytime $\mathrm{PaCO}_{2}$ decreased significantly over the follow-up period in the group I patients treated with auto-EPAP as compared with fixed-EPAP (Table 2). Other parameters of gas exchange improved in the both groups, without significant differences.

As shown in Table 3, the patient comfort and subjective dyspnea assessment comparing auto-EPAP and fixed-EPAP during iVAPS treatment. A notable decrease in dyspnea sensation with auto-EPAP $(7.9 \pm 1.8$ (T0) vs $3.5 \pm 1.1$ (T2), $\mathrm{p}-=0.001)$ and fixed-EPAP $(7.7 \pm 1.9$ (T0) vs $3.4 \pm 1.6$ (T2), $p=0.001$ ) was noted, but this improvement was not significant. However, auto-EPAP demonstrated a significant improvement in comfort when compared with fixed-EPAP modality. However, the overall level of satisfaction in patients receiving auto-EPAP was significantly increased.

Treatment compliance was assessed from cumulative use (data not shown, $\mathrm{p}=0.433$ ) or mean night-time use $347 \pm 145$ and $350 \pm 144 \mathrm{~min}$ for 
Table 2. The time course of the study outcomes using auto-EPAP and fixed-EPAP) during iVAPS treatment in COPD patients

\begin{tabular}{|c|c|c|c|c|c|c|c|c|c|}
\hline & \multicolumn{4}{|c|}{$\begin{array}{c}\text { Group I } \\
\text { Auto-EPAP modality } \\
(\mathrm{n}=25)\end{array}$} & \multicolumn{4}{|c|}{$\begin{array}{c}\text { Group II } \\
\text { Fixed-EPAP modality } \\
(\mathbf{n}=25)\end{array}$} & \multirow[t]{2}{*}{$\mathbf{P}$} \\
\hline & TO & $\mathrm{T1}$ & T2 & $\mathbf{P}$ & TO & T1 & T2 & $\mathbf{P}$ & \\
\hline $\mathrm{RR}$ [bpm] & $16.4 \pm 3.4$ & $15.4 \pm 4.6$ & $16.6 \pm 4.6$ & 0.231 & $16.3 \pm 5.6$ & $15.7 \pm 5.4$ & $16.5 \pm 4.5$ & 0.132 & 0.231 \\
\hline HR [beat/min] & $102 \pm 3$ & $99.3 \pm 4$ & $97.2 \pm 5$ & 0.65 & $100 \pm 8.1$ & $96.2 \pm 3$ & $97.7 \pm 4$ & 0.23 & 0.34 \\
\hline $\mathrm{PH}$ & $7.37 \pm 0.03$ & $7.37 \pm 0.02$ & $7.38 \pm 0.01$ & 0.231 & $7.37 \pm 0.02$ & $7.37 \pm 0.02$ & $7.38 \pm 0.02$ & 0.453 & 0.543 \\
\hline $\mathrm{PaCo}_{2}[\mathrm{~mm} \mathrm{Hg}]$ & $62.7 \pm 6.6$ & $52.3 \pm 4.1$ & $52.2 \pm 3.1$ & 0.001 & $63.3 \pm 6.5$ & $59.1 \pm 7.1$ & $55.2 \pm 6.2$ & 0.001 & 0.001 \\
\hline $\mathrm{PaO}_{2}[\mathrm{~mm} \mathrm{Hg}]$ & $73.1 \pm 9.2$ & $74.7 \pm 5.9$ & $76.3 \pm 8.5$ & 0.012 & $72.8 \pm 10.4$ & $73.2 \pm 9.3$ & $76.6 \pm 10.9$ & 0.043 & 0.321 \\
\hline $\mathrm{SaO}_{2}[\%]$ & $95 \pm 2$ & $95 \pm 2$ & $96 \pm 1$ & 0.342 & $95 \pm 2$ & $95 \pm 1$ & $96 \pm 1$ & 0.214 & 0.235 \\
\hline $\mathrm{PaO}_{2} / \mathrm{FiO}_{2}$ & $262.2 \pm 38$ & $278.3 \pm 36$ & $278.3 \pm 34$ & 0.231 & $264.5 \pm 34$ & $275.3 \pm 37$ & $279.3 \pm 40$ & 0.432 & 0.546 \\
\hline
\end{tabular}

Data presented as mean ((SD). $\mathrm{RR}$ — respiratory rate; bpm — breaths per minute; $\mathrm{HR}$ — heart rate; $\mathrm{PaCO}_{2}$ — partial arterial carbon dioxide tension; PaO arterial oxygen tension; $\mathrm{SaO}_{2}$ - arterial oxygen saturation; $\mathrm{TO}$ - baseline assessment; $\mathrm{t}(\mathrm{T} 1)$ after 3 day of intervention and (T2) after 5 days

Table 3. Dyspnea and comfort score during the study period

\begin{tabular}{|c|c|c|c|c|c|c|c|c|c|}
\hline & \multicolumn{4}{|c|}{$\begin{array}{c}\text { Group I } \\
\text { Auto-EPAP modality } \\
(\mathbf{n}=25)\end{array}$} & \multicolumn{4}{|c|}{$\begin{array}{c}\text { Group II } \\
\text { Fixed-EPAP modality } \\
(\mathbf{n}=25)\end{array}$} & \multirow[t]{2}{*}{$\mathbf{P}$} \\
\hline & TO & T1 & T2 & $\mathbf{P}$ & TO & T1 & $\mathrm{T} 2$ & $\mathbf{P}$ & \\
\hline Dyspnea score & $7.9 \pm 1.8$ & $4.2 \pm 1.3$ & $3.5 \pm 1.1$ & 0.001 & $7.7 \pm 1.9$ & $4.3 \pm 1.7$ & $3.4 \pm 1.6$ & 0.001 & 0.231 \\
\hline Comfort score & $6.3 \pm 2.1$ & $3.9 \pm 2.1$ & $3.4 \pm 1.8$ & 0.001 & $6.4 \pm 1.09$ & $4.9 \pm 1.5$ & $3.7 \pm 1.6$ & 0.001 & 0.002 \\
\hline Level of satisfaction & $6.2 \pm 1.9$ & $6.4 \pm 1.9$ & $7.9 \pm 2.01$ & 0.001 & $6.18 \pm 1.3$ & $6.2 \pm 1.6$ & $7.2 \pm 1.9$ & 0.001 & 0.002 \\
\hline
\end{tabular}

auto-adjusting and fixed-EPAP modality, respectively, $\mathrm{p}=0.256$ ) over the study periods and was similar for the two groups. Table 4 showed the ventilatory pattern response recorded during the 5-day period. Mean tidal volume tended to be higher in auto-EPAP $698 \pm 213 \mathrm{~mL}$ compared with $628 \pm 178 \mathrm{~mL}$ in fixed-EPAP modality ( $\mathrm{p}$ $=0.001^{*}$ ). Air leak was observed to be lower in auto-adjusting mode $2.5 \pm 1.3$ vs $3.7 \pm 2.2 \mathrm{~L}$ per minute in fixed-EPAP.

\section{Discussions}

Intelligent volume-assured pressure support (iVAPS) is a hybrid mode of servoventilation providing constant automatic adjustment of pressure support (PS) to achieve target ventilation determined by the patient's requirements. Hence, the purpose of the study was to compare auto-titrating auto-EPAP versus fixed-EPAP during iVAPS treatment in patients with COPD and chronic hypercapnia as regards treatment efficacy, and the level of patients satisfaction.
The current study noted a higher amount of $\mathrm{PaCO}_{2}$ levels decreases within a shorter period of time in patients treated with auto-titrating iVAPS mode. This response with automatic mode is more pronounced within the first day of usage, and significantly greater reductions in $\mathrm{PaCO}_{2}$ levels take place during a follow-up period. In agreement with our results, Gursel et al. investigated the efficiency of AVAPS-AE mode in hypercapnic respiratory failure. The authors found $10 \mathrm{~mm} \mathrm{Hg}$ reduction in $\mathrm{PaCO}_{2}$ levels had been achieved within a short time period in the auto-titrating group [11]. The more efficient $\mathrm{PaCO}_{2}$ reduction in auto-titrating mode may be attributed to the higher tidal volume that was achieved. Recently, two further studies reported that this ventilation mode has been effective and safe in patients with chronic obstructive pulmonary disease (COPD) and hypercapnic respiratory failure $[12,13]$.

The target tidal volume of the two groups was set similarly $6 \mathrm{~mL} /$ ideal $\mathrm{kg}$ of the patient; but, the actual tidal volume was significantly higher 
Table 4. Ventilatory pattern response recorded during both modalities

\begin{tabular}{|c|c|c|c|}
\hline Pressure & $\begin{array}{c}\text { Auto-EPAP } \\
(\mathrm{n}=25)\end{array}$ & $\begin{array}{l}\text { Fixed-EPAP } \\
(\mathrm{n}=25)\end{array}$ & P-value \\
\hline Mean EPAP [cm H $\left.\mathrm{H}_{2} \mathrm{O}\right]$ & $6.5 \pm 1.1$ & $7.9 \pm 2.1$ & 0.001 \\
\hline Mean IPAP [cm H$\left.{ }_{2} \mathrm{O}\right]$ & $17.2 \pm 2.2$ & $17.3 \pm 3.1$ & 0.342 \\
\hline Mean pressure support $\left[\mathrm{cm} \mathrm{H}_{2} \mathrm{O}\right]$ & $9.2 \pm 2.1$ & $8.5 \pm 1.8$ & 0.002 \\
\hline Leak [L/min] & $2.5 \pm 1.3$ & $3.7 \pm 2.2$ & 0.001 \\
\hline $95^{\text {th }}$ centile leak $[\mathrm{L} / \mathrm{min}]$ & $16.2 \pm 2.1$ & $23.7 \pm 3.2$ & 0.001 \\
\hline Mean tidal volume [mL] & $698 \pm 213$ & $628 \pm 178$ & 0.001 \\
\hline
\end{tabular}

Data are shown as mean \pm SD. EPAP — expiratory positive airway pressure; iVAPS — intelligent volume-assured positive airway pressure support; bpm — breaths per minute; $\mathrm{mL}$ - milliliters

in the auto-titrating group despite a lower PS. This might be explained by better elimination of upper airway resistance and improved lung mechanics. Orr et al. in their study compared the effects of one night on auto-titrated EPAP in addition to intelligent volume-assured pressure support iVAPS-AE with fixed-EPAP iVAPS in 38 patients with heterogeneous etiology for chronic hypercapnic respiratory failure (neuromuscular disease, chronic obstructive pulmonary disease, obesity hypoventilation). The authors noted that auto-EPAP mode delivered a higher EPAP than the fixed-EPAP mode $(10.2 \pm 3.0$ vs $7.0 \pm 3.3 \mathrm{~cm}$ $\mathrm{H}_{2} \mathrm{O}, \mathrm{p}=0.0002$ ), but there was no difference in the level of pressure support provided. They noticed the increase in EPAP was associated with stable ventilatory parameters; tidal volume (Vt) and transcutaneous carbon dioxide $\left(\mathrm{tcCO}_{2}\right)$, suggesting no deleterious effect on pulmonary mechanics [14]. Therefore, auto-adjusting iVAPS has an important role in treating hypercapnia in COPD patients.

In our study on COPD patients, it appears noteworthy that auto-EPAP modality was associated with better patient comfort and satisfaction. The major theoretical advantage of the VT mode is providing automatic adjustment of pressure support to achieve target alveolar ventilation. This allows the ventilator to maintain a given tidal volume in an environment of deteriorating respiratory compliance. Its application was thought to be more tolerable and effective in hypercapnic COPD patients; as the result of dynamic changes in airway resistance and lung mechanics thus potentially suggesting a more favorable physiological benefit if used for a longer period. As compared with the previous conventional PS modes, iVAPS has been shown to provide better comfort and satisfaction and a more efficient decrease of $\mathrm{PCO}_{2}[4,15,16]$. Such improvements in adherence and comfort could have an impact on long-term outcomes in COPD patients.

The current study demonstrated lower levels of air leak in auto-EPAP despite higher pulmonary volumes and EPAP levels. A study by McArdle et al. investigated patients with chronic hypoventilation using iVAPS with auto-EPAP or fixed-EPAP over two separate nights of attended PSG. They found that the leak was similar in the two groups. However, there was less frequent sleep technologist and mask adjustment for leak intervention [18]. In contrast, a study by Gursel et al. noted higher air leaks reached by AVAPSAE. The reason for this may be using a single limb machine that had an intentional leak. Thus, a further investigation is required to observe if higher air leaks may change patient-ventilator synchrony [11].

The strength of the study lies in its randomized design, using the random assignment technique and the patients unaware of the device mode being used. Though, the risk of bias is not achieved. Also, we studied the subjects already using NIV, in whom previous EPAP settings were available, hence minimizing the need for manual titration. All COPD cases were subjected to lung function test, muscle strength and arterial blood gas information; instead of relying on the referring clinician diagnosis and patient history.

There was some limitation in our study. Firstly, the small number of patients. Secondly, this randomized study was evaluated for a short time (5 days) in stable hypercapnic COPD patients; however long-term outcomes were not addressed. Hence, future research is needed to evaluate the efficacy of auto-EPAP iVAPS treatment on sleep quality, exacerbation rate, hospital admission, quality of life. Thirdly, VT devices have sophisticated algorithms and a wide range of technical features in its usage; unfortunately, 
we did not study ventilator variables as automatic adjustment of triggering and cycling thresholds that may have an important role in device effectiveness. Fourth; we have not done polysomnography for patients to exclude sleep disorders as it is costy.

\section{Conclusions}

iVAPS is clearly an interesting adjunct to the tools available to clinicians in the field of hypercapnic ventilatory failure; this study is to compare clinical or subjective benefit in terms of using auto-titrating or fixed-EPAP during iVAPS perceived in a sample of patients with stable hypercapnic COPD. Auto-titrating iVAPS has been shown to provide higher pulmonary volumes and a more efficient decrease of $\mathrm{PaCO}_{2}$ resulting in improved patient comfort and satisfaction. Further investigations are needed to address long-term outcomes of auto-titrating iVAPS treatment on COPD exacerbation or hospital admissions and quality of life.

\section{Ethical approval and consent to participate}

The research received ethical approval from the Ethics Committee of the Faculty of Medicine. The data were confidential. All procedures in the current study were performed according to the ethical standards of the institutional research committee.

\section{Institutional review board statement}

This study was approved by the Faculty of Medicine Ethics and Scientific Research Committees.

\section{Acknowledgements}

We want to thank all respiratory nurses in Assuit university hospital. We want to thank all patients who participated in the study.

\section{Conflict of interest:}

None declared.

\section{References:}

1. World Health Organization. The global burden of disease: 2004 update. 2008. www.who.int/healthinfo/global burden_disease/ GBD_report_2004update full.pdf (June 11, 2014).

2. Calverley PMA. Respiratory failure in chronic obstructive pulmonary disease. Eur Respir J Suppl. 2003; 47: 26s-30s, doi: 10.1183/09031936.03.00030103, indexed in Pubmed: 14621114.
3. Struik FM, Sprooten RTM, Kerstjens HAM, et al. Nocturnal non-invasive ventilation in COPD patients with prolonged hypercapnia after ventilatory support for acute respiratory failure: a randomised, controlled, parallel-group study. Thorax. 2014; 69(9): 826-834, doi: 10.1136/thoraxjnl-2014-205126, indexed in Pubmed: 24781217.

4. Kelly JL, Jaye J, Pickersgill RE, et al. Randomized trial of ,intelligent' autotitrating ventilation versus standard pressure support non-invasive ventilation: impact on adherence and physiological outcomes. Respirology. 2014; 19(4): 596-603, doi: 10.1111/resp.12269, indexed in Pubmed: 24661390.

5. Nilius G, Katamadze N, Domanski U, et al. Non-invasive ventilation with intelligent volume-assured pressure support versus pressure-controlled ventilation: effects on the respiratory event rate and sleep quality in COPD with chronic hypercapnia. Int J Chron Obstruct Pulmon Dis. 2017; 12: 1039-1045, doi: 10.2147/COPD.S126970, indexed in Pubmed: 28408814.

6. Global Initiative for Chronic Obstructive Pulmonary Disease (GOLD). COPD: global strategy for the diagnosis, management, and prevention of COPD. 2018. https://goldcoped.org/ (July 17, 2018).

7. Quanjer PH, Tammeling GJ, Cotes JE, et al. Lung volumes and forced ventilatory flows. Report Working Party Standardization of Lung Function Tests, European Community for Steel and Coal. Official Statement of the European Respiratory Society. Eur Respir J Suppl. 1993; 16: 5-40, indexed in Pubmed: 8499054.

8. Black LF, Hyatt RE. Maximal respiratory pressures: normal values and relationship to age and sex. Am Rev Respir Dis. 1969; 99(5): 696-702, doi: 10.1164/arrd.1969.99.5.696, indexed in Pubmed: 5772056 .

9. Gift AG, Narsavage G. Validity of the numeric rating scale as a measure of dyspnea. Am J Crit Care. 1998; 7(3): 200-204, indexed in Pubmed: $\underline{9579246}$.

10. Vargas F, Thille A, Lyazidi A, et al. Helmet with specific settings versus facemask for noninvasive ventilation. Crit Care Med. 2009; 37(6): 1921-1928, doi: 10.1097/CCM.0b013e31819fff93, indexed in Pubmed: 19384209.

11. Gursel G, Zerman A, Basarik B, et al. Noninvasive auto-titrating ventilation (AVAPS-AE) versus average volume-assured pressure support (AVAPS) ventilation in hypercapnic respiratory failure patients. Intern Emerg Med. 2018; 13(3): 359-365, doi: 10.1007/s11739-018-1821-2, indexed in Pubmed: 29512020.

12. Murphy PB, Arbane G, Ramsay M, et al. Safety and efficacy of auto-titrating noninvasive ventilation in COPD and obstructive sleep apnoea overlap syndrome. Eur Respir J. 2015; 46(2): 548-551, doi: 10.1183/09031936.00205714, indexed in Pubmed: 26113686.

13. Coughlin S, Liang WE, Parthasarathy S. Retrospective assessment of home ventilation to reduce rehospitalization in chronic obstructive pulmonary disease. J Clin Sleep Med. 2015; 11(6): 663-670, doi: 10.5664/jcsm.4780, indexed in Pubmed: 25766720.

14. Orr JE, Coleman J, Criner GJ, et al. Automatic EPAP intelligent volume-assured pressure support is effective in patients with chronic respiratory failure: A randomized trial. Respirology. 2019; 24(12): 1204-1211, doi: 10.1111/resp.13546, indexed in Pubmed: $\underline{31012225}$.

15. Crisafulli E, Manni G, Kidonias M, et al. Subjective sleep quality during average volume assured pressure support (AVAPS) ventilation in patients with hypercapnic COPD: a physiological pilot study. Lung. 2009; 187(5): 299-305, doi: $10.1007 /$ s00408-009-9167-1, indexed in Pubmed: 19672655.

16. Magdy DM, Metwally A. Effect of average volume-assured pressure support treatment on health-related quality of life in COPD patients with chronic hypercapnic respiratory failure: a randomized trial. Respir Res. 2020; 21(1): 64, doi: 10.1186/ s12931-020-1320-7, indexed in Pubmed: 32143652 .

17. McArdle N, Rea C, King S, et al. Treating chronic hypoventilation with automatic adjustable versus fixed EPAP intelligent volume-assured positive airway pressure support (iVAPS): A randomized controlled trial. Sleep. 2017; 40(10), doi: $10.1093 /$ sleep/zsx136, indexed in Pubmed: 28958052. 